be useful steel. He failed entirely in this; he never succeeded in producing merchantable steel from ordinary English cast-iron by this method.

The Bessemer process, as at present conducted, consists in first oxidising simultaneously all or nearly all the carbon and silicon, and then adding to the decarburised iron a new dose of carbon, by means of a known quantity of spiegeleisen of known composition; thus reverting to the old Sheffield principle of first bringing the cast-iron to the state of wrought or decarburised iron, and then adding carbon to convert it into steel.

It is commonly represented that the failure of the early attempts at direct steel-making by the Bessemer process arose simply from the difficulty of determining the right moment at which to stop the blow, and thereby to regulate the proportion of carbon; and that the whole advantage of the spiegeleisen is the means it affords of doing this. Dr. Percy says:-"In attempting to produce steel by the methods specified by Bessemer, it has hitherto been found very difficult, if not impracticable, at least in this country, to ascertain with certainty when decarburisation has proceeded to the right extent, and when therefore the blast should be stopped. Accordingly the plan now adopted is to decarburise perfectly, or nearly so, and then add a given proportion of carbon in the state in which it exists in molten spiegeleisen, the precise composition of which should of course be known."* Neither in Dr. Percy's nor any other account of the Bessemer process do I find that the necessity of complete decarburisation as a means of completely separating the silicon is fairly appreciated.

If merchantable steel could be made from English pigiron by simply stopping the blow before complete decarburisation, Mr. Bessemer would surely have produced some good steel in the course of his long and costly efforts which preceded the idea of introducing the spiegeleisen, for it must be remembered that the quantity of carbon required in steel cxtends over a very wide range - that steel may contain from $0^{\prime} 40$ to $2^{\circ} 00$ per cent. of carbon, and that steel with every degree of carburisation within this wide range is in demand in the market at good prices, provided it be free from phosphorus, silicon, \&c. Nothing is practically easier than to stop the blow at such a moment as shall ensure a degree of carburisation somewhere between this wide range; and there can be no doubt that, in his early experiments, Mr. Bessemer, like other inventors of direct processes, made an abundance of iron that was duly carburised within the above-stated limits, although he failed to produce useful steel.

Dr. Percy's qualification, "at least in this country" is rather curious. He has probably learned that steel has been directly made in Sweden (though he does not mention it in his work) by the Bessemer process, and he seems to attribute this to the superior ability of the Swedish operators, enabling them "to ascertain with certainty when decarburisation has proceeded to the right extent." I differ entirely from Dr. Percy in this conclusion, being convinced that Mr. George Brown, the manager of the Bessemer Department at the Atlas Works, Sheffield, who was the furst to work the Bessemer process with commercial success, is better able (on account of his much greater experience and thorough knowledge of the work) than any of the Swedish manufacturers, to determine when any required degree of decarburisation has been attained. It is not the superior skill of the Swedish operators that has enabled them to make steel directly by the Bessemer process; but the fact that they, like the Styrian workers, used a very superior charcoal-iron to start with; and that the blowing out of all the carbon was not absolutely necessary for the sufficient purification of this quality of iron.

\section{W. Mattieu Williams}

\section{ON THE NATURAL LAWS OF MUSCULAR EXERTION}

THE experiments published by Mr. W. Stanley Jevons, in NATURE on the 3oth June last, illustrate well two laws of muscular exertion which were established by experiments made by myself in 1862 and 1863. These laws may be thus stated :-

Law I. The work given out by a single group of muscles, in a single contraction, is constant.

Law 2. When the same group of muscles is kept in constant action, the total work done by them until fatigue sets in, multiplied by the rate at which they are compelled to work, is constant.

Mr. Jevons' first series of experiments, in which different weights were thrown by the arm to various distances on level ground, illustrates the first law. In throwing weights in this manner, the arm, after a little practice, instinctively pitches the weight at the angle corresponding to the maximum range, and as the maximum range is proportional to the square of the velocity of projection, it may be used to replace that velocity squared, in estimating the work done by the arm.

The total work done is the same as if the weight used and the weight of the arm were concentrated at the centre of oscillation of the loaded arm, regarded as a compound pendulum.

Let us assume

$$
\begin{aligned}
w & =\text { weight held in hand; } \\
x & =\text { weight of arm; } \\
v & =\text { velocity of centre of oscillation. }
\end{aligned}
$$

By Law $I$, the work done is constant and is represented by

Let

$$
(w+x) v^{2}=\text { const. }
$$

$$
\begin{aligned}
V & =\text { velocity of hand; } \\
l & =\text { radius of oscillation; } \\
a & =\text { length of arm. }
\end{aligned}
$$

then

$$
v=V \frac{l}{a}
$$

It is easy to show (assuming the arm to be a uniform cylinder) that

$$
\frac{l}{a}=\frac{2}{3} \cdot \frac{(3 w+x)}{(2 w+x)}
$$

By means of (2) and (3), equation (I) becomes

$$
\frac{(w+x)(3 w+x)^{2}}{(2 w+x)^{2}} \times R=A
$$

where $R$ denotes the range (proportional to $V^{2}$ ) and $A$ denotes a constant, if Law I be true.

Mr. Jevons' experiments give the following corresponding values of $w$ and $R$.

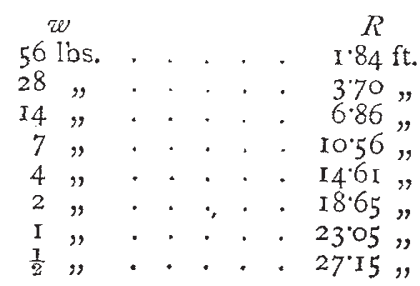

We are required to assign certain values to $x$ and $A$, which will make equation (4) best coincide with the eight simultaneous values of $w$ and $R$ found by observation.

I find by trial that these values are

$$
\begin{aligned}
& x=8.1 \text { libs. } \\
& A=262.2 .
\end{aligned}
$$

If we solve equation (4) for $R$, we find

$$
R=\frac{A(2 w+x)^{2}}{(i+x)(3 x+x)^{2}}
$$


Substituting for $A$ and $x$ in this equation their values above given, we can obtain by calculation the distances to which the weights should be thrown, according to Law I.

We thus obtain the following comparison between theory and observation.

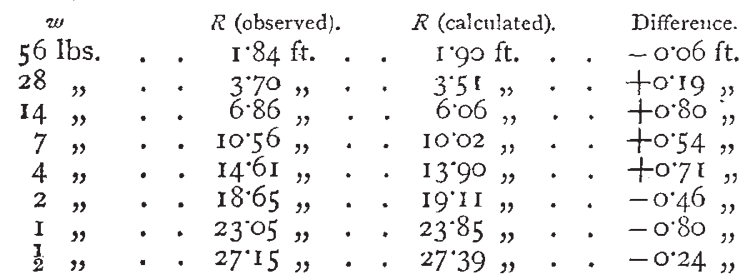

The agreement here shown between observation and calculation founded on $\mathrm{Law} \mathrm{r}$, is quite as complete as the agreement between observation and the empirical formula used by Mr. Jevons, which may be written, in the notation of the present paper, as follows :-

$$
(2 w+7 \cdot 8) R=23 \mathrm{r}^{\circ} 3 \text {. }
$$

Mr. Jevons' third series of experiments consisted in holding various weights on $t^{\text {t. }} \mathrm{c}$ hand extended horizontally, and noting the time during which the weights could be so held. The following are the weights and times observed :-

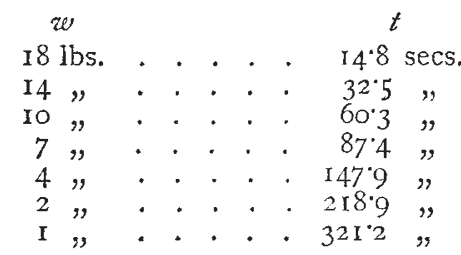

Omitting the first of these experiments I find that Law 2 satisfactorily accounts for the remaining six, and gives a constant, which is nearly identical with that obtained from my own experiments made in I863.

When the arm is extended horizontally, if allowed to fall through an indefinitely small arc, the centre of oscillation falls like a free body under the influence of gravity, and the muscles then lift back the arm through the same arc, and this goes on continuously until the muscles are tired out.

Let us use the following notation :-

$w$ and $x$ are, as before, the weight held in the hand and the weight of the arm.

$l=$ radius of oscillation ;

$a=$ distance of centre of gravity of loaded arm from centre of shoulder joint;

$\delta s=$ small space through which the centre of oscillation falls ;

$n^{*}=$ number of such falls during

$t=$ whole time required to fatigue the muscles.

The total work done by the muscles in the time $t$, is evidently

$$
(w+x) \frac{a}{l} n \delta s
$$

but, $n \delta s$ varies as $t$, and, therefore, the total work done varies as

$$
(w+x) \frac{a}{l} t
$$

The rate of work is evidently proportional to

$$
(w+x) \frac{a}{l}
$$

and since, by Law 2, the total work done before fatigue multiplied by the rate of work is constant, we obtain

$$
(w+x)^{2} \frac{a^{2}}{l^{2}} t=\text { Const. }
$$

*I have ascertained the number $n$ from acoustical observations made on
And, since

we find, by substitution,

$$
\frac{a}{l}=\frac{3}{4} \cdot \frac{(2 w+x)^{2}}{(w+x)(3 w+x)^{\prime}}
$$

$$
\frac{(2 w+x)^{4}}{(3 w+x)^{2}} t=a \text {. }
$$

This equation (9) is the statement of Law 2 , as applied to Mr. Jevons' experiments ; and we are required to find values for $x$ and $a$, which wiil make equation (9) best correspond with the given observations.

I find, by trial, that the following values will answer best :-

$$
\begin{aligned}
& x=74 \mathrm{lb} . \\
& a=22,05 \circ .
\end{aligned}
$$

If we solve equation (9) for $t$, we find

$$
t=A \frac{(3 w+x)^{2}}{(2 w+x)^{4}} .
$$

From this equation, substituting the values of $x$ and $A$, we obtain the following comparison of observation and theory :

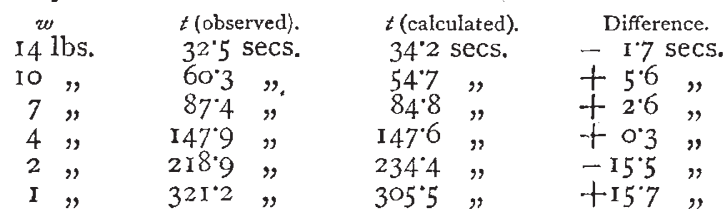

This comparison is very satisfactory, the differences being much less than possible errors of observations. Mr. Jevons' experiments further show that the useful effect has a maximum corresponding to a certain weight. This weight, which gives the maximum of useful effect, may be readily calculated from Law 2 .

By equation (10), the useful effect is

$$
w t=A \cdot \frac{w(3 w+x)^{2}}{(2 w+x)^{4}}
$$

This will be a maximum, when

or when

$$
(2 w+x)(9 w+x)=8 w(3 w+x) ;
$$

or when

$$
\begin{gathered}
6 w^{2}-3 x w-x^{2}=0 ; \\
w=\frac{3+\sqrt{33}}{\mathrm{I} 2} x ;
\end{gathered}
$$

or,

$$
w=0.73 x
$$

Substituting for $x$ its value 74 lb., we find for the weight that gives the maximum useful effect, $w=5^{\circ} 4 \mathrm{olb}$.

The useful effect observed by Mr. Jevons was as follows:

$$
\begin{aligned}
& \text { I } 8 \text { lbs. . . . . . . . . . Use'ul effect } 266 \\
& \text { I4 }, . . . \quad . \quad . \quad . \quad . \quad 455 \\
& \text { I0 \%. . . . . . . } 603 \\
& 7 \% . . . .6 .6 \mathrm{I} 2 \\
& 4 \% \text {. . . . . . . . } 592 \\
& 2 " \text {. . . . . . . . } 438
\end{aligned}
$$

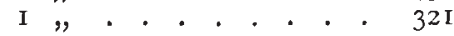

The actual maximum corresponds to $5 \% 4 \mathrm{lb}$. lying between $7 \mathrm{lb}$. and $4 \mathrm{lb}$.

I may observe, in conclusion, that the difference of weights $x$ of the arm, found in the two sets of experiments is quite natural.

In the experiments in which the arm was held out horizontally, its weight, $74 \mathrm{lb}$, is the weight of the arm below the centre of the shoulder joint.

In the experiments in which the weights are thrown by the arm, a portion of the shoulder blade is in motion, in addition to the simple arm, and the total weight becomes 8. I l b.
SAMUEL HAUGHTON 